\title{
ES(INS)CRITAS DO CORPO DANÇANTE: NARRATIVAS SINGULARES E PLURAIS
}

\section{NEILA CRISTINA BALDI}

Universidade Federal da Bahia

RESUMO O presente texto discute a relação da dança com a narrativa. Primeiramente, o artigo mostra que a narrativa pode ser enredo da dança e a dança pode ser uma narrativa. Posteriormente, discorre sobre a narrativa, a partir do campo da Autobiografia, e como pode potencializar a dança ao mesmo tempo em que da dança podem emergir narrativas autobiográficas. A partir da perspectiva de que criamos corpografias, o texto mostra como o trabalho com essas narrativas dançantes, com o aporte da Autobiografia e da Educação Somática, pode ser autoformativo, de importância tanto para artistas quanto para professores(as).

Palavras-chave: Narrativa. Dança. Autobiografia. Educação somática.

\section{ABSTRACT WRITINGS/RECORDS OF THE DANCING BODY: SINGULAR AND PLURAL NARRATIVES}

This academic paper aims to discuss the relationship between dance and narrative. Firstly, this article shows that the narrative can be the plot of a dance, as well as the dance can be a narrative. Posteriorly, it argues about the narrative from the Autobiography perspective and how it can develop the dance at the same time that, from the dance, it may emerge autobiographical narratives. From the perspective that we create bodygraphies, this paper shows how the work with dancing narratives, with contribution of Autobiography and Somatic Education, can be self-taught and important to both artists and teachers.

Keywords: Narrative. Dance. Autobiography. Somatic education.

\section{RESUMEN ESCRITOS/REGISTROS DEL CUERPO DANZANTE:}

\section{NARRATIVAS SINGULARES E PLURALES}

El presente texto académico discute la relación de la danza con la narrativa. Primeramente el artículo muestra que la narrativa puede ser enredo de la danza y la danza puede ser una narrativa. Posteriormente, discurre sobre la narrativa a partir del campo de la Autobiografia y como se puede potencializar la danza al mismo tiempo en 
que de la danza pueden emerger narrativas autobiográficas. A partir de la perspectiva de que criamos cuerpografias, el texto muestra como el trabajo con esas narrativas danzantes, con el aporte de la Autobiografía y de la Educación Somática, podrían ser autoformativas, de importancia tanto para artistas cuanto para maestros.

Palabras clave: Narrativa. Danza. Autobiografia. Educación somática.

Desde o começo percebemos que a dança é afim à escrita, que o movimento que percorre uma entrelaça a outra, que as duas são feitas de algo único.

(TIBURI; ROCHA, 2012, p. 130.)

Dança e escrita têm íntimas relações. Durante muito tempo, a dança cênica ocidental apoiou-se em libretos para a sua composição coreográfica. Ou seja, partia de uma escrita a priori - um enredo - para o seu desenvolvimento. Mas, além da escrita ter sido inspiração para a dança, a própria dança produz uma escrita: a coreografia. Desta forma, do mesmo modo que a dança escreve, também se inscreve no corpo daquele(a) que dança, assim como o ser dançante escreve suas inscrições enquanto dança.

A narrativa - principalmente literária - serviu muito à dança cênica ocidental, ao longo dos últimos séculos. Mas, desde o século XX, a narrativa de si também tem sido usada, principalmente como pesquisa para a criação cênica. Ou seja, trata-se de outro tipo de narrativa, que não necessariamente linear.

No campo das Artes Cênicas, sobretudo no teatro, as narrativas de si têm potencializado criações cênicas (GIORDANO, 2014) e permeado processos formativos (FIGUEIREDO, 2014). $\mathrm{Na}$ dança, esse tipo de pesquisa se concentra, principalmente, na criação coreográfica. Mas a pesquisa autobiográfica tem potencial maior, uma vez que a dança se faz no/com o corpo e nosso corpo escreve e é inscrito por nossas vivências, o que significa que a narrativa de si pode potencializar outras pesquisas que não apenas as de criação cênica.
A narrativa de si, na dança, pode ser, então, pesquisa para a criação cênica, servir como processo formativo de futuros(as) professores(as) de dança e/ou bailarinos(as), assim como a própria dança pode ser uma narrativa autobiográfica, um modo de investigação do campo da Autobiografia. Fortuna (2012, p. 182) nos lembra que a autobiografia não se restringe à escrita com caracteres alfabéticos no papel, pois “[...] a autobiografia refere-se às várias formas de escrita de si e a grafia é tudo isso que deixa um traço, um signo". Desta forma, as histórias de vida podem ser "traçadas com a pena ou a palavra, através de expressão corpórea, da música, da dança, do jogo, das imagens", sendo que "os signos traçados podem ser encorpados ou etéreos, bidimensionais ou tridimensionais, duradouros ou fugazes" (STACCIOLI, 2005, p. 58, apud FORTUNA, 2012, p. 182). Isto porque nossas memórias existem "[...] também através dos gestos e dos modos de organização corpórea. A memória é viva e não um arquivo, mas um sistema dinâmico" (TOLEDO, 2013, p. 77).

0 presente texto pretende discutir as es(ins)critas do corpo dançante, na perspectiva de que são, ao mesmo tempo, singulares, mas também plurais. Para isso, aponta como, pouco a pouco, a pesquisa autobiográfica vem tomando a dança, mostra qual a relação da dança com a escrita - narrativa ou não -, e de como as inscrições são material de pesquisa em dança, tanto do ponto de vista didático quanto artístico.

A partir do entendimento de que construímos ao longo de nossas vidas corpografias, o 
texto pretende - embasado na Autobiografia e na Educação Somática - discutir como a dança tem potencial para a narrativa de si, como a Autobiografia é material para a dança e como os procedimentos de ensino de dança, baseados nesses dois campos, auxiliam aquele(a) que dança ou que pretende ser professor(a) de dança a entender sua formação e se autoformar. Os procedimentos aqui discutidos foram construídos ao longo de minha carreira docente, tanto no âmbito universitário quanto em cursos livres.

\section{Narrativa como pesquisa: autobiografia}

O campo da pesquisa autobiográfica, constituído na segunda metade do século XX, é bastante amplo e, neste sentido, segundo Tânia Fortuna (2012, p. 169) “[...] é tão fácil perder-se em imprecisões conceituais quanto é fácil dispersar-se em preciosismos terminológicos". Os termos histórias de vida, narrativas de si, autobiografias, biografias educativas, entre outros, constituem o campo e diferenciam-se quanto aos procedimentos de pesquisa. Neste texto, narrativas ou escritas de si serão usadas como sinônimo de autobiografia, pois coaduno com o pensamento de Fortuna (2012, p. 167), de uma definição ampla do campo, que inclui pesquisas que analisam como "[...] os indivíduos vivem e representam a sua existência [...]". Assim, o modo de chegada a esta análise pode ser pelo movimento e, no caso da discussão deste texto, pela dança.

A pesquisa autobiográfica tem sido muito usada, no campo da Educação, principalmente na investigação sobre a formação docente. Diversos(as) autores(as) do campo da Autobiografia enxergam-no como um método de pesquisa, mas também pedagógico. Souza (2006) afirma que a pesquisa narrativa evidencia e aprofunda aspectos das experiências educativas e da formação dos sujeitos, valorizando as experiências de vida tanto pessoais quanto profissionais, propiciando-lhes o conhecimento de si, ao mesmo tempo em que elucida os significados que os sujeitos conferem às suas vidas.

Josso (2004) diz que as experiências revividas pelos diversos métodos de pesquisa deste campo - ela se refere às narrativas de formação, mas aqui a discussão se amplia não contam apenas o que a vida ensinou, mas o que se aprendeu. Além disso, segundo ela, nem sempre é fácil compreender que “[...] esta metodologia favorece um conjunto de aprendizagens que vão muito além de um processo de conhecimento de si no registro psicológico" (JOSSO, 2004, p. 171). Quando se trabalha com práticas corporais, este entendimento parece ainda mais dificil, pois a tendência de muitas pessoas é pensar em dança-terapia, sem a compreensão dos aspectos gerais que o campo da Autobiografia envolve.

\section{A dança e a narrativa: da linearidade à autobiografia}

A emergência da dança cênica no Ocidente está relacionada à dança da corte. Segundo Bourcier (2001), o momo ou mascarada surge na corte europeia, no século XIV, como entremez para os pratos dos banquetes. No século XVI, surge o balé da corte e, com ele, o profissionalismo na dança. Dançavam-se histórias, que eram publicadas nos chamados libretos. Até 1611, de acordo com Bourcier (2001), o único libreto publicado havia sido o do Ballet comique de la reine, e a mitologia fornecia a maior parte dos enredos dessas estórias. Interessante notar que, apesar de etimologicamente coreografia significar escrita da dança, não havia, no entanto, a notação das mesmas. Ou seja, a dança escrevia-se no espaço cênico e nos corpos dos(as) bailarinos(as), sem registros para uma posterior remontagem. 
Ao longo do desenvolvimento da dança cênica ocidental, ligada ao balé clássico, apesar da narrativa estar relacionada a uma história a ser contada - na maior parte das vezes baseada em mitos - o desenvolvimento técnico da dança fez com que surgissem os chamados divertimentos - números coreográficos dentro do espetáculo que mais pretendiam mostrar o virtuosismo técnico do que contar uma história. Ou seja, no meio das "histórias dançadas", havia coreografias que, muitas vezes, não tinham relação direta com o enredo a ser contado, mas que serviam para que os(as) bailarinos(as) mostrassem seu grau técnico. A dança cênica ocidental, que até ali trabalhava a partir de uma perspectiva de narrativa linear, tinha essa linearidade parcialmente quebrada pelos divertimentos. Foi por isso que Jean-Georges Noverre propôs uma reforma no balé - que chamava de balé de ação, e excluiria aquilo que ele denominou de mecanicismo, virtuosismo. No entanto, essa reforma, de fato, só ocorreu muito tempo depois. Em sua época, o que ocorreu foi uma mudança nos enredos que, no século XIX, passam a tratar das mulheres etéreas, como as sílfides. São dessa época muitos dos chamados balés de repertório, remontados até hoje, como Giselle (1841) e Coppélia (1870).

A chegada do século XX significa uma revolução e a quebra com a narrativa. No início do século XX surge o Balé Russo, de Diaghilev, que, com A sagração da primavera (1913) - coreografia de Nijinsky - provoca uma revolução estética na dança - ainda baseada em uma história -, podendo ser considerada uma obra precursora da dança moderna. A chamada dança moderna, como técnica e como estética, é uma quebra no balé clássico, tanto do ponto de vista do uso do corpo - não mais as extremidades, mas ênfase no tronco - quanto do ponto de vista do enredo a ser discutido em cena - não necessariamente histórias, mas o foco está na expressividade e nas questões humanas - assim como há uma mudança em relação à música. Como dançar contos de fadas se o mundo, na primeira metade do século passado, passava por duas grandes guerras? Ribeiro (1997) fala que esse foi o movimento de "queda do corpo": saímos de uma dança que se utilizava da sapatilha de ponta para "[...] elevar o corpo da bailarina para que esta se pudesse metamorfosear num ser etéreo [...]" (RIBEIRO, 1997, p. 8) e nos deparamos, com as pioneiras da dança moderna, com a reivindicação da representação da vida real, ou seja, inicia-se “[...] um percurso do corpo para si, ainda que, mediado primeiramente por uma aproximação do corpo à realidade social, política e artística de então" (RIBEIRO, 1997, p. 9).

A partir da segunda metade do século XX e no momento atual, a dança cênica ocidental começa a trabalhar a narrativa a partir de outra perspectiva: narrar-se. Narrar-se a si como dança - movimento pelo movimento, sem necessariamente ter uma história para contar - a si como corpo - pesquisa sobre a materialidade do corpo, sua estrutura física e possibilidades de movimento, inclusive os mais improváveis, mas também o uso dos movimentos cotidianos como ferramentas de criação - e a si como indivíduo - as questões pessoais do(a) criador(a), suas angústias, sua vida. Surge a autobiografia como potência criativa para a dança. Ribeiro (1997, p. 20) diz que os artistas passam a se concentrar no corpo - seu e do público - “[...] e o tomam como objecto privilegiado de trabalho e reflexão: o corpo expressa o corpo".

$\mathrm{Na}$ contemporaneidade, diversas são as maneiras de se pesquisar para a criação coreográfica e a autobiografia é uma delas. De acordo com Peres (2014, p. 81), a “utilização de dados autobiográficos em composições cênicas emerge na cena moderna e contemporânea como uma possibilidade do sujeito ser 
criador de sua própria arte". A autora, assim como outros(as) teóricos(as) da dança, cita Pina Bausch como uma das expoentes no uso da autobiografia em cena, isto por que:

\begin{abstract}
A Dança-Teatro de Pina Bausch concentrou-se na reconstrução simbólica da experiência dos bailarinos, deu-lhes voz e liberdade para responder a estímulos diversos e a representá-los sob forma de movimento. [...] Abordagem de movimentos sem as amarras da técnica tradicional, [...] que não busca um modelo de corpo homogeneizado, mas que se interessa justamente pela variedade e acolhe sem priorizar, todos os movimentos do corpo. (GREBLER, 2008, p. 103)
\end{abstract}

Seu processo de criação partia do chamado método das perguntas e respostas, em que o(a) bailarino(a) respondia a perguntas ou propostas que fundamentam “[...] o processo criativo na história e na verdade do intérprete, estimulando-o à criação através de uma relação parceira" (GREBLER, 2008, p. 103). Era um método que, de acordo com Fernandes (2007), permitia aos/às intérpretes revisitar suas memórias, reconstruindo física e verbalmente suas histórias. Segundo Bausch:

Quando comecei a coreografar, nunca tratei a dança como só 'coreografia', mas como expressão de sentimentos. Cada peça é diferente, difícil de se colocar em palavras. Num trabalho, cada coisa está entrelaçada - a música, o cenário, o movimento e tudo que é dito. Eu não sei onde uma coisa para e a outra começa, e eu não preciso analisar isto. Limitaria o trabalho se não fosse analítica. (BAUSCH, 1985 apud TRAVI, 2013, s.n.)

Sua dança sai da narrativa linear e passa a narrar sentimentos, conceitos etc., pois busca uma dança que se relacionava com as vivências, percepções, histórias e emoções de cada um(a), e que permita a “[...] consciência do corpo quanto à sua própria história enquanto tópico simbólico e social em constante transformação" (FERNANDES, 2007, p. 31). O(a) dan- çarino(a) de Pina Bausch não dança a sua história do ponto de vista linear, nem de fatos e acontecimentos, mas fragmentos de memórias que dizem respeito a temas específicos: como amor, solidão etc. Isso por que:

A memória tece lembranças assentadas na afetividade de acontecimentos, miúdos ou grandiosos, e no impacto e eloquência que impuseram a observadores participantes, que nestes acontecimentos se engajaram integralmente. O movimento de uma lembrança vibra fora dos compassos rígidos e desvitalizados de um conceito permanente, de uma ideia eterna, de um princípio abstrato: o ânimo que fomenta é gerado na espessura de uma experiência. Uma experiência possui plasticidade: não fixa saberes, remetendo a nossa atenção para os sentidos inesgotáveis de uma práxis. Possui perceptibilidade: oferece traços inconfundiveis que a singularizam. Possui realizabilidade: impõemse como realidade incontestável através das diversas interpretações que pode sustentar. (GONÇALVES FILHO et al, 1988 apud MACHADO, 2012, p. 72)

Neste sentido, são danças singulares, mas também plurais. Singulares porque partem da singularidade de cada indivíduo, do seu pensamento, sua memória a respeito de algo - mesmo que, em muitas vezes, a criação de uma pessoa venha a ser dançada por outra, como ocorre em inúmeros processos coreográficos - mas, ao mesmo tempo, essa dança é plural porque os temas são universais e, além disso:

[...] as histórias que contamos sobre nós mesmos e que, segundo alguns, nós dirigimos a outros, longe de nos jogar numa intimidade inacessivel, têm por efeito articular nosso espaço-tempo individual ao espaço-tempo social. (DELORY-MOMBERGER, 2012, p. 75)

Outro modo de abordar a autobiografia na criação em dança é, por exemplo, o trabalho do brasileiro Luiz Abreu, com as obras: Samba do Crioulo Doido (2004) e Máquina de desgastar gente (2006), que tratam de questões de gêne- 
ro, sexualidade e raça (LEAL, 2013). Em Samba do Crioulo Doido, segundo Santana (2010, p. 76), a dança “[...] está intimamente ligada com a maneira pela qual o próprio criador dialoga consigo mesmo, em relação a suas vivências autobiográficas". Por sua vez, Em Máquina de desgastar gente, o criador pediu para que dançarinos buscassem “[...] recordações de infância, especificamente das avós, como de suas experiências profissionais" (LEAL, 2013, p. 281282). Com esse material e tendo o livro $O$ povo brasileiro (Darcy Ribeiro) como referencial teórico, foi criada a coreografia que busca narrar a história do negro no Brasil.

Para Leal (2013, p. 88), ao “reencenar/coreografar dados autobiográficos cria-se a possibilidade de refletir sobre esses acontecimentos, lançando luz ao que antes era escuridão". Ora, isso significa que o movimento de narrar-se a partir da escrita do movimento no espaço é semelhante ao narrar-se por meio da escrita no papel - as chamadas escritas de si, narrativas autobiográficas etc. Ou seja, “ao narrar-se o sujeito desvela-se para si e revela-se para os outros" (ABRAHÃO, 2004 apud WEGNER, 2011, p. 29).

Do mesmo modo que a narrativa de si presente nas obras de Pina Bausch, nas de Abreu e em outros inúmeros exemplos da dança contemporânea que se utilizam da autobiografia em seus processos criativos, não se trata de um trabalho terapêutico, nem muito menos de cunho tão pessoal que não venha a falar com o público em geral. Isso porque, segundo Giordano (2015, p. 88):

[...] as dimensões pessoais do bailarino se cruzam com as projeções coletivas e assim é tecida uma teia múltipla de agenciamentos. É nessa relação que encontramos o ponto fundamental que revela a importância da autobiografia na cena contemporânea. Porque nesse sentido encontramos um lugar político para falar sobre as narrativas de si quando elas estão relacionadas à sua capacidade de alteridade.

\section{Corpografias}

A mudança no tipo de narrativa presente na dança cênica ocidental significou também uma alteração no modo da área enxergar o corpo, “[...] uma queda: do corpo abstracto e desmaterializado ao corpo físico, energético e corporal" (RIBEIRO, 1997, p. 8). Durante muito tempo a dança viu o corpo como instrumento e o balé clássico ainda hoje - com algumas exceções é um bom exemplo deste pensamento. A visão de corpo, até a emergência da dança moderna, era mecanicista e, a partir disso, a prática da dança era vista:

[...] como uma atividade mecânica que valoriza o virtuosismo quantitativo - o quão alto, quão rápido, quão grande. Exercícios e seqüências são repetidas inúmeras vezes até se tornarem virtualmente automáticas. Cada parte do corpo pode ser trabalhada isoladamente, 'orquestrada' com outras partes. Acredita-se, predominantemente, que o corpo de alguma forma saberá como integrar-se e que as diferenças nos niveis de aprendizagem individual encontrarão resoluções. (WOODRUFF, 1999, p. 33)

Neste pensamento, o corpo apenas escrevia no espaço a partir de movimentos - nascidos, muitas vezes, de histórias ficcionais ou mitos, como discutido anteriormente - como um lápis que risca o papel em branco, que, por vezes, precisamos afinar a ponta. A metáfora do lápis, em algumas técnicas de dança, é muito forte, porque o pensamento era mesmo de “afinamento", adestramento deste corpo. Nesta perspectiva, o corpo escrevia, mas não era inscrito. Ou melhor, não se reconheciam suas inscrições.

Segundo Ribeiro (1997, p. 16), “simultaneamente à aceleração do processo capitalista o corpo tornou-se mercadoria e investiu na figura do humano". As Artes do Corpo, na sua avaliação, lutaram contra a mercantilização do corpo, a partir do século passado e, portanto, mudaram sua visão de corpo. A partir da emer- 
gência da dança moderna, o corpo passa a ser visto como sujeito: eu sou corpo, não tenho um corpo. O corpo não é mais objeto. Além disso, da segunda metade do século passado em diante, a dança passou a se aproximar de outras práticas corporais, como aquelas que hoje estão dentro da Educação Somática - campo de conhecimento constituído de práticas como Feldenkrais, Alexander etc., criadas pelos chamados reformadores do movimento, ${ }^{1}$ que têm em comum a proposição da unidade corpomente e partem da premissa de "[...] que nenhum ser humano é igual ao outro e de que estas diferenças deveriam ser respeitadas e mantidas" (STRAZZACAPPA, 2009, p. 49). Nos anos 1970, o filósofo Thomas Hanna, enxergando os pontos de conexão entre as diversas práticas, denominou o campo como Educação Somática.

Teóricos(as) da Educação Somática (BATSON, 2009; EDDY, 2009; HANNA 1976, 1986) acreditam que o que vivemos nos afeta em todos os sentidos, inclusive na nossa estrutura anatômica. É por isso que Green (2002, p. 117, tradução nossa) diz que "o alinhamento é o reflexo do que nós somos, o que experimentamos e o que o mundo significa para nós".2

Esta ruptura, iniciada no século passado, no entanto, não é total. Não significa que a emergência de um pensamento deu fim a outro. Para Ribeiro (1994), na dança, atualmente, coexistem dois pensamentos de corpo: o corpo $\mathrm{Hi}-\mathrm{Fi}$, de alta fidelidade na execução de suas performances; e o corpo-livro, que ultrapassa a questão atlética, pensado do ponto de vista existencial, político, social, histórico etc. Para ele, o maior exemplo deste segundo corpo é a produção de Pina Bausch. Voltamos, então,

1 Termo usado por Márcia Strazzacappa para se referir aos pioneiros no desenvolvimento e na codificação de técnicas corporais específicas que tinham como preocupação o movimento (ou a recuperação do movimento).

2 No original: "The alignment is a reflection of who we are, what we experience, and what the world means to us". à questão da narrativa, de outra visão de narrativa, do pensamento sobre a narrativa de si, uma vez que, como bem lembram teóricos(as) da Autobiografia, os acontecimentos que "[...] tocam cada sujeito, vão sendo registrados corporalmente, encaminhando toda uma maneira de assimilar, sentir e interagir com o mundo a sua volta" (ZANELLA, 2011, p. 9).

Este corpo-sujeito que a dança buscou pode ser entendido, então, como um corpo escrito e inscrito, um corpo que escreve e inscreve, que produz, portanto, uma corpografia. É um corpo que conta nossas memórias - ou seja, escreve - e é inscrito por elas. É por isso que Kofes (1985, p. 47) diz que o corpo aprende “[...] e, no que ensina o corpo, ele se expressa: no andar, dormir, dançar, nadar, nos gestos, posturas das mãos, no jeito de olhar". Ou seja, nós somos, então, produto do que vivenciamos e vamos reverberar este ensinamento no nosso gesto, no nosso agir. Nosso corpo literalmente fala. Mas também escrevemos e inscrevemos na gente e nos outros.

Vianna e Castilho (2002), duas teóricas da dança, afirmam que nossos gestos, nossa postura e nossa expressão facial dizem mais de nós do que podemos imaginar. "Cada um traz escrito, em seu corpo, uma memória de vida, uma história, um contexto familiar" (VIANNA; CASTILHO, 2002, p. 24). Mas este pensamento não se dá apenas entre dançarinos(as) ou entre teóricos(as) da Educação Somática - campo no qual parte da dança contemporânea vem se apoiando. As fisioterapeutas Marie-Madeleinde Béziers e Suzanne Piret (1992, p. 13) dizem que: "[...] todo gesto é carregado de psiquismo, e o investimento do fator psicológico no movimento é análogo ao da motricidade no psiquismo". Assim, como visto, muito mais que o psiquismo, mas toda a cultura, pois é um corpo social, histórico, político etc. Quando dançamos, então, tudo isso está ali, explícito ou implícito, e nossas práticas de dança vão aju- 
dando a nos formar, a criar novas corpografias. É por isso que Mônica Ribeiro (2013, p. 57) afirma que a "dança é não somente o que lembro, mas principalmente o que esqueço e dá lugar a outras articulações de sentido".

$O(A)$ dançarino(a) e o(a) professor(a) de dança carregam, então, em seus fazeres, essas memórias. É por isso que Lenora Lobo, em entrevista ao jornal Correio Brasiliense, em 21 de agosto de 2011, disse que: "Ao subir ao palco, o bailarino não leva apenas sua experiência artística, mas suas memórias, sua vida familiar, profissional, as atividades que pratica. [...]. Não existe separação. A pessoa e o bailarino são a mesma coisa" (LOBO, 2011 apud VIEIRA, 2016, p. 169). Ou seja, do mesmo modo que não existe, no meu entendimento - a partir da Educação Somática -, uma separação de corpo e mente e, sim, um sujeito integrado, não há também uma separação dos papéis que exercemos em nosso dia a dia: o eu que dança é o mesmo eu que namora, que vai ao cinema, que sofre com a perda de alguém etc. Assim, tudo isso que vivemos, dentro e fora da dança, vai se manifestar na nossa dança, no nosso jeito de ser.

\section{Narrativas de si dançantes}

Entendido que criamos corpografias, como a dança pode ajudar o sujeito na narrativa de si e como a narrativa de si pode ajudar na dança? E como tudo isso nos forma ou nos ajuda a entender nossa formação como bailarinos(as) e professores(as) de dança? Para responder a estas perguntas, trago, então, dois campos do conhecimento: a Educação Somática e a Autobiografia. Procedimentos embasados nestes dois campos, acredito, ajudam a dar estas respostas. Importante ressaltar que em nenhum momento estou falando, por exemplo, de dança-terapia, mas de dança como arte e de seus processos formativos tanto para aquele(a) que quer apenas dançar quanto para aquele(a) que deseja ensinar dança ou para quem deseja ambas as profissões. Importante ressaltar também que algumas tendências pedagógicas mais progressistas, na dança, como a Pedagogia feminista, trabalham com autobiografia, em uma perspectiva de que os(as) professores(as) explorem com seus/suas alunos(as) as “[...] biografias individuais, os eventos históricos e as relações de poder" (MIDDLETON, 1994 apud STINSON, 1995. p. 36). Mas, aqui, o que proponho é discutir uma dança autobiográfica a partir de procedimentos que nascem dos princípios da Educação Somática e da Autobiografia e não apoiada na Pedagogia feminista.

A Educação Somática é “[...] um termo guarda-chuva usado para juntar experiências práticas corporais que privilegiam experiências subjetivas"3 (FORTIN, 2002, p. 128, tradução nossa), e trabalha com práticas corporais, a partir da integração corpomente e de princípios como o privilégio à informação que vem do corpo, a descoberta pessoal, a autorregulação, o reconhecimento de padrões, a busca por um corpo saudável e a mudança de ritmo do/ no movimento da/na aprendizagem. O campo tem técnicas e métodos sistematizados, mas também abordagens - procedimentos que usam os princípios gerais ou que nasceram da mescla de sistematizações. Em meu trabalho docente, parto das abordagens somáticas e não de uma técnica ou método sistematizado.

Por outro lado, o campo da Autobiografia entende que nossa formação é um processo contínuo, estamos sempre nos formando, e, além disso, compreende o quanto a nossa sub-

3 No original: “[...] an umbrella term used to assemble experiential bodily practices that privilege subjective experience". (FORTIN, 2002, p. 128) 
jetividade é importante - assim como a Educação Somática. As narrativas ou escritas de si, proporcionadas pela Autobiografia, permitem que pensemos: “[...] nas marcas produzidas - o que fizeram conosco, para então pensarmos no que podemos fazer conosco a partir de agora" (OLIVEIRA, 2011, p. 132). A partir desse entendimento do campo da Autobiografia, fui construindo procedimentos embasados nesta perspectiva.

Relato aqui, portanto, alguns procedimentos que partem do meu pensamento sobre os dois campos do conhecimento, de modo a pensar nessas narrativas que a dança produz, de nossas corpografias. Os procedimentos foram criados e vivenciados ao longo de minha experiência docente, tanto em espaços formais quanto informais, incluindo a formação de futuros(as) artistasdocentes ${ }^{4}$ em curso universitário.

Vou tentar responder, então, à primeira pergunta: como a dança pode ajudar o sujeito na narrativa de si? Parto do pressuposto de que a narrativa de si pode ser tanto escrita quanto imagética e cinestésica. Ana Carolina Mundim (2013, p. 267) diz que "se o corpo é inscrição é, portanto, texto". o próprio corpo é texto e, ele, em movimento, produz escrituras. Posso, então, movimentar-me para narrar-me?

Um procedimento interessante para isso é o que chamo de Estações - de um lado a outro na sala, o(a) bailarino(a) deve imaginar de três a cinco espaços [a quantidade vai depender da idade da pessoa e será determinada previamente pelo(a) docente], sendo cada um deles representativo de uma fase da vida: primeira infância, segunda infância, adolescência, vida adulta e maturidade. Que movimentação cada espaço-tempo me conduz? O que ele me inspi-

4 Considero que colocar o hífen entre artista e docente dá uma ideia de dicotomia. Um artista docente não é meio artista, nem meio docente, é $100 \%$ os dois, porque em toda dimensão criativa há uma dimensão pedagógica. ra? Como é transitar de um para outro, sem necessariamente seguir uma cronologia? A ideia não é reproduzir gestos dessas faixas-etárias, mas permitir que o espaço-tempo imaginário nos conduza ao movimento, que ele nos permita rememorar, de modo que, assim, "[...] as memórias são reescritas sempre que ativadas [...]" (BASTOS, 2013, p. 183). Do ponto de vista artístico, pode-se escolher fragmentos da movimentação de cada estação e criar uma pequena célula coreográfica. Nesta escolha, por mais que pensemos do ponto de vista estético, é claro que nossa subjetividade estará presente, pois nenhuma escolha é aleatória. Quando levantamos movimentos, em dança - em qualquer pesquisa de movimentação, oriunda ou não da autobiografia - temos sempre de fazer escolhas. Já dizia Wally Salomão (2001): “a memória é uma ilha de edição". Se o próprio rememorar já é editar, imagina olhar para tudo o que foi produzido de movimento e escolher? Este processo de escolha, segundo Dominicé (2010a, p. 88), faz com que:

\section{[...] Esforçando-se por selecionar no seu passa- do educativo o que the parece ter sido forma- dor na sua vida, o sujeito do relato biográfico põe em evidencia uma dupla dinâmica: a do seu percurso de vida e a dos significados que lhe atribui; nunca se limita a fazer um simples balanço contabilístico de acontecimentos ou de determinados momentos.}

Aqui é importante ressaltar que o autor se refere ao passado educativo, mas se pensarmos que estamos sempre nos formando e que nos formamos nos mais diversos espaçostempos, então, esse passado educativo não se situa apenas no âmbito escolar, mas em qualquer espaço.

Do ponto de vista pedagógico, este tipo de procedimento permite a emergência de uma dança própria e não a reprodução de movimentos já codificados (vindos de técnicas como o balé clássico, o jazz, a dança moderna 
etc.). Isso é importante não só para aquele(a) que dança, mas também para aquele(a) que vai ensinar. Muitas vezes, o(a) aluno(a) de dança acredita que dançar seja apenas e tão somente produzir movimentos codificados e não enxerga dança em outros movimentos - considera que o que não é codificado não é dança - e, por vezes, não acredita que possa produzir sua dança.

Além de considerar os aspectos artísticos e pedagógicos específicos da dança, há que se pensar que esta narrativa de si produzida em movimento é também uma escrita autoformativa, pois, como afirma Peres (2011, p. 73), “na medida em que o sujeito se pensa, muitos aspectos do vivido podem vir a tona para contribuir com o processo de formação posterior".

A segunda pergunta (como a narrativa de si pode ajudar na dança?) pode ser pensada a partir da Autobiografia, de uma forma geral, não de uma técnica ou método do campo da pesquisa autobiográfica. Neste caso, pode emergir tanto dos procedimentos utilizados por Pina Bausch quanto pelos criados por outros(as) artistas que trabalham com a autobiografia para a criação cênica e já discutidos anteriormente. Pode também aparecer em sala de aula - para fins didáticos - ou na sala de ensaio - para fins artísticos - de formas variadas.

Trazer material pessoal para a sala de aula pode ajudar na pesquisa de movimentos nessa dança autobiográfica: brinquedos, cartas, fotografias etc. Brinquedos podem ser usados em aula de dança tanto para crianças quanto para adultos. Para além da memória afetiva, o manuseio do objeto nos conduz a movimentações que trazem outras memórias cinestésicas, e assim sucessivamente. Quais são as possibilidades de movimento da boneca? 0 que ela traz para mim, para o meu movimento? E o carrinho, a corda, o bambolê? A ideia não é que façam mímica de movimentos que os brinquedos produzem, mas que se deixem descobrir o que o brinquedo pode trazer para si e para o seu movimento. Pode-se pesquisar também a partir da memória daquele brinquedo. Do mesmo modo que, em outras pesquisas de movimento, a partir desta exploração, cria-se uma partitura de movimento. Em uma primeira vista, pode parecer que este tipo de exploração não pode ser formativa, do ponto de vista da autobiografia, mas há que se pensar na memória do movimento, nas escritas e inscrições que produzimos ao longo de nossas vidas. Além disso, não podemos esquecer que "nossos corpos proporcionam um mapeamento emocional de quem somos e de como fomos modelados pela sociedade dominante. $A$ exploração das memórias ou dos sentidos corporais [...] pode nos levar à análise e à ação" (SHAPIRO, 1998, p. 39). Não se pode esquecer o que pode derivar deste dançar - e isso tem relação com o que o(a) professor(a) de dança vem a propor depois desta experiência, mas também de como o sujeito dançante absorve a experiência.

Este tipo de procedimento descrito acima tem uma significação muito importante, pois traz objetos pessoais, ou seja, estamos trabalhando com a realidade concreta de cada um(a), para além da realidade subjetiva. Considerar, desta forma, o contexto do(a) educando(a), no sentido de Freire (1987), mas bem mais amplo, que não apenas a sua realidade ao redor mas, sobretudo, sua realidade subjetiva. Freire (1987) dizia que, em uma educação problematizadora, os conteúdos se organizam e se constituem na visão de mundo dos(as) estudantes.

Neste sentido, a vida dos(as) alunos(as) se torna currículo. A vida também subjetiva e não apenas na realidade ao redor. Porque os(as) teóricos(as) da Autobiografia (JOSSO, 2004; DELORY-MOMBERGER, 2012; FERRAROTTI, 2010; PERES, 2011) têm demonstrado que o subjeti- 
vo não apenas é conhecimento, mas também é social. Há uma dimensão social no particular e há a singularidade. A partir desta perspectiva, a dança autobiográfica pode ser entendida como uma experiência. Assim, coaduno com o pensamento de Contreras e Pérez de Lara (2010, p. 32, tradução nossa) de que: “Preocupar-se com a educação como experiência é abrir-se a uma escuta do que realmente nos sucede, assim como abrir-se a uma escuta do que verdadeiramente significa e nos significa isso que nos sucede". ${ }^{5}$

Por fim, como tudo isso nos forma ou nos ajuda a entender nossa formação como bailarinos(as) e professores(as) de dança? Como autobiografia e dança entrelaçam-se para a nossa formação? Aqui é importante ressaltar a necessidade da reflexão com/na ação. Contreras (2002, p. 111) diz que:

Não nos encontramos, portanto, diante de uma separação entre o pensar e o fazer, pois a ação não é, nesse caso, uma realização de decisões técnicas. 0 pensar e o fazer vão se entrelaçando no 'diálogo' gerado entre a ação e suas consequências, as quais levam a uma nova apreciação do caso.

É claro, no entanto, que algumas experiências favorecem mais esta reflexão que outras. Portanto, como professores(as), devemos estar atentos a isso. Mas também não podemos esquecer que nem sempre é no ato, na vivência de uma experiência, que "as fichas caem". Como bem lembra Acaso (2013), em numerosas vezes é muito tempo depois que nos damos conta de que compreendemos algo. Neste sentido, ter diários de bordo - com imagens e/ou escritos - durante as aulas, pode ajudar nesse processo. Não se trata de pensar nos diários como registros das aulas, dos exercícios pro-

5 No original: “Preocuparse por la educación en cuanto que experiencia es abrirse a la escucha de lo que realmente nos sucede, así como abrirse a la escucha de lo que verdaderamente significa, y nos significa, eso que nos sucede". (CONTRERAS; PEREZ DE LARA, 2010, p. 32) postos etc., mas, sim, compreendê-los como parte do processo, em um escreverdançando - enquanto dança, explora, registra no diário o que ocorre, o que the move, o que sente etc. $\mathrm{Ou}$ posteriormente, quando algo no mundo fora da aula the faz rememorar algum fato da aula. Fotografar ou filmar alguns momentos da aula também pode ser útil - desde que haja um momento para que estas reproduções sejam vistas e revistas -, do mesmo modo que proporcionar aos/às alunos(as) escritas reflexivas. Em minhas classes de dança, trabalho com pelo menos dois tipos de escritas reflexivas, além do diário de bordo: inventários pessoais e reflexões sobre o processo.

Os inventários pessoais são textos próximos às chamadas escritas de si ou histórias de vida, ou seja, escritos em que os(as) alunos(as) contam sua história de vida, o que lhes foi significativo, qual a relação do que viveram ao longo da vida e a dança - uma vez que esta é meu objeto de ensino. Para ajudá-los(as), levanto algumas questões: como foi a relação com o meu corpo? Eu brincava de que? Que tipos de movimentos buscava? Como encontrei a dança? O que dancei ao longo de minha vida? Ao longo de um semestre letivo, esses textos são reescritos pelo menos duas vezes - uma delas depois de uma vivência rememorativa de suas vidas e outra no fim do semestre. Por sua vez, as reflexões sobre o processo ocorrem ao final de cada unidade didática e se dão em sala, após uma vivência que possa auxiliá - los(as) a se conectar consigo. Josso (2004) fala da importância de momentos de relaxamento que, segundo ela, é condição para estarmos disponiveis e facilita a rememoração.

Um procedimento que uso nas aulas de dança, em pelo menos uma aula, é o que chamo de Vivência Rememorativa. Considero-o importante do ponto de vista de resposta à última questão abordada. Geralmente começo esta aula por um momento de "esvazia- 
mento" - chama-se meditação ativa, de Osho. ${ }^{6}$ Posteriormente, cada um(a) escolhe um lugar na sala para deitar e vou conduzindo-os(as) à rememoração por fases de vida. Esclareço, no início da vivência, que o movimento é bemvindo, ou seja, não é preciso estar deitado(a) e imóvel apenas relembrando, e que aos seus lados existem papéis e canetas que podem ser usados para anotações. A partir de indicações como: imagine que está no útero de sua mãe e está nascendo, como era esse bebê etc. até a chegada à fase adulta. É claro, no entanto, que nem sempre é fácil executar esse tipo ação e, como afirma Martini Lani-Bayle (2012), as tomadas de consciência podem ser desestabilizadoras e suscitar resistências à narrativa, mesmo quando o motivo não aparece de forma clara. Como professora, tenho de ter um olhar atento ao que ocorre, pois muitas vezes é no movimento que o sentimento se expressa - o rasgar a folha por uma raiva, o esmurrar a parede, o cair no choro etc. As anotações e percepções dessa vivência podem servir para a revisão do inventário pessoal e sua respectiva reescrita, pois: [...] o que o adulto diz de sua história não é idêntico em todos os momentos de sua vida, nem em todos os contextos nos quais se exprime" (DOMINICÉ, 2010a, p. 88).

Ao longo de um semestre, as vivências de sala de aula - as narrativas em movimento bem como as escritas pessoais - diários de bordo, inventário e reflexões - fazem emergir diversas questões formativas para o(a) futuro(a) profissional de dança - em qualquer que seja a sua ênfase, tanto como artista quanto como professor(a) ou atuando como artistadocente. É possivel perceber, por exemplo, quais são os padrões de movimento constantes - ou seja, quais são as movimentações que a pessoa tende a repetir - e, muitas vezes, com-

6 O indiano Osho desenvolveu uma série de meditações que partiam do princípio do movimento, do chacoalhar e dançar até a exaustão para, posteriormente, ficar em silêncio. preender a origem delas. Do mesmo modo, ao longo do processo, muitas vezes emergem a compreensão de escolhas estéticas - o que para um(a) futuro(a) artista é muito importante. Ou são levantadas questões em relação ao fazer pedagógico: repito o que meus/minhas professores(as) faziam? Valeska Oliveira (2011) nos lembra que os territórios que adentramos, quando estamos escrevendo sobre nossas vivências, nos trazem à mente significados construídos sobre docência a partir da nossa experiência como alunos(as). A autora afirma que a produção destas narrativas, em cursos de licenciatura, permite que a pessoa que escolheu a docência como profissão reveja seus repertórios, suas visões de professor, e problematize modelos, práticas e comportamentos (OLIVEIRA, 2011).

\section{Singularidades e pluralidades}

Processos autobiográficos em dança - para a criação cênica, para fins didáticos ou quaisquer que sejam - são processos formativos singulares, mas também plurais.

A singularidade desses processos talvez seja a questão mais visivel, pois, como nos lembra Cunha (2012, p. 101), o "exercício de desvelamento que caracteriza a pesquisa autobiográfica fundamenta-se na memória. A memória assinala a nossa singularidade, direcionando as possibilidades de ser e fazer". Mais que isso, é extremamente singular o eusujeito descobrir a sua própria dança a partir de sua própria vida - dos fatos, dos objetos, fotografias e memórias; assim como descobrirse a si e a seus processos formativos dançando. Sobre esta questão das singularidades e pluralidades, Dominicé (2010b, p. 199) afirma que:

[...] Quaisquer que sejam os parâmetros comuns - a família de origem, a escola, os grupos de adolescentes, a formação profissional, o exercício do trabalho - a biografia educativa 
põe em relevo processos de formação próprios de cada narrativa da história de vida. 0 processo não é, portanto, uma medida comum de formações diferentes. Enquanto noção, exprime essas diferenças.

No entanto, como bem lembra Larrosa (2006, p. 25), "toda escritura pessoal, enquanto escritura, contém vestígios das palavras e histórias recebidas". Voltamos, portanto, às corpografias, às nossas es(ins)critas, ao fato de es(ins)crevermos... Além disso, não podemos esquecer que "todas as narrações autobiográficas relatam, segundo um corte horizontal ou vertical, uma práxis humana. [...] Toda a vida humana se revela, até nos seus aspectos menos generalizáveis, como a síntese vertical de uma história social" (FERRAROTTI, 2010, p. 44), o que significa que nossa singularidade está permeada por uma pluralidade.

A pluralidade presente nas corpografias e nas narrativas dançantes aqui expostas vão além, porém, do fato de sermos permeados e afetados pelos outros. São plurais também porque este eu-sujeito enxerga no outro a si, e vice-versa, e enxerga em si e no outro o coletivo:

Por meio do processo crítico de refletir sobre experiências vividas, os estudantes são capacitados a interpretar as relações sociais e individuais que vivem, e podem começar a entender seu próprio poder de transformar e recriar essas relações e, consequentemente, seu próprio mundo. (SHAPIRO, 1998, p. 36, grifo da autora)

Ou como diz Bolivar (2012), a narrativa é um modo dos indivíduos darem sentido a si e ao mundo. Nunca é apenas pessoal, mas também nunca é de todo coletivo. 0 singular e o plural estão presentes o tempo todo nesse processo.

Ao vivenciar práticas corporais que permitem refletir sobre sua história, ao escrever sobre elas - em movimento ou na folha do papel -, ao rememorar sua vida e inscrições corpo- rais, o(a) aluno(a) consegue perceber o que o forma e visualizar o que pretende formar. Segundo Josso (2004, p. 72):

Este movimento retrospectivo do pensamento provoca tomadas de consciência, tanto pela pluralidade das leituras possiveis de uma mesma experiência, como pela evolução geral [...] de visão de mundo ou, cosmogonia pessoal, que cada um progressivamente constituiu e interiorizou diante das suas necessidades de dar sentido à sua vivência, à sua trajetória, aos seus laços consigo mesmo, com o outro e com o meio humano e natural.

A dança autobiográfica aqui descrita, o trabalho a partir das corpografias do sujeito dançante permite também a emergência do(a) pesquisador(a), tanto da parte do(a) aluno(a) que participa da vivência, quanto do(a) professor(a) que propõe, pois, de acordo com Betânia Ramalho, Isauro Nunez e Clermont Gauthier (2004, p. 28), o(a) professor(a)-pesquisador(a) é o “[...] profissional que participa na produção de saberes com métodos e estratégias sistematizadas, utilizando a pesquisa como mecanismo de aprendizagem". No caso de licenciaturas em Dança, este tipo de trabalho se torna ainda mais relevante na formação desse artistadocente, que pode ver a pesquisa na sua prática cotidiana.

Acredito, assim, que o tipo de experiência descrita neste texto pode fazer com que a aula de dança seja:

[...] um lugar onde os estudantes façam conexões entre o pessoal e o social; desenvolvam suas habilidades perceptivas, imaginativas e sensuais; encontrem suas próprias vozes; validem seus sentimentos e suas capacidades de compaixão, e adquiram poder por meio da afirmação de sua capacidade de serem co-criadores do mundo que vivem. (SHAPIRO, 1998, p. 44)

Encerro esta discussão a respeito da singularidade e da pluralidade dessas narrativas dançantes lembrando que o tempo todo elas são formativas, independente de estarmos ou 
não em um curso de graduação em Dança, uma vez que a "formação depende do que cada um faz do que os outros quiseram, ou não quiseram, fazer dele" (DOMINICÉ, 2010a, p. 95). E que: “[...] Por ser um processo, a formação não se dá

\section{Referências}

ACASO, María. Reduvolution: hacer la revolución en la educación. Barcelona: Paidós, 2013.

BATSON, Glenna. Somatic Studies and Dance. International Association for Dance Medicine and Science, [s.l.], 17 set. 2009. Disponível em: <http://www. iadms.org>. Acesso em: 23 out. 2015

BASTOS, Marcus. Práticas e políticas para criação de memórias culturais em ambientes programáveis. In: SILVA, Monica Toledo (Org.). Performances da memória. Belo Horizonte: Impressões de Minas, 2013. p. $179-216$

BÉZIERS, Marie-Madeleine; PIRET, Suzanne. A coordenação motora: aspecto mecânico da organização psicomotora do homem. 3. ed. São Paulo: Summus Editorial, 1992.

BOLIVAR, Antonio. Dimensiones epistemológicas y metodológicas de la investigación (auto)biográfica. In: PASSEGI, Maria da Conceição; ABRAHÃO, Maria Helena Menna Barreto. (Orgs.). Dimensões epistemológicas e metodológicas da pesquisa (auto)biográfica. Tomo I. Natal: EDUFRN; Porto Alegre: EDIPUCRS; Salvador: EDUNEB, 2012. p. 27-70.

BOURCIER, Paul. História da dança no ocidente. São Paulo: Martins Fontes, 2001.

CONTRERAS, José. PÉREZ DE LARA, Núria. La experiencia y la investigación educativa. In: CONTRERAS, José; PÉREZ DE LARA, Núria. (Comps.). Investigar la experiencia educativa. Madrid: 2010, Ediciones Morata. p. 21-86.

CONTRERAS, José. A autonomia de profesores. São Paulo: Cortez, 2002.

CUNHA, Jorge Luiz da. Pesquisas com (auto)biografias: interfaces em tempos de individuação. In: PASSEGGI, Maria da Conceição; ABRAHÃO, Maria Helena a conhecer de uma só vez nem num lugar preciso. É falada de várias maneiras e em diversos contextos [...]" (DOMINICÉ, 2010b, p. 213). Estamos sempre nos formando e sempre criando novas corpografias.

Menna Barreto. (orgs.). Dimensões epistemológicas e metodológicas da pesquisa (auto)biográfica. Tomo I. Natal: EDUFRN; Porto Alegre: EDIPUCRS; Salvador: EDUNEB, 2012. p. 95-114.

DELORY-MOMBERGER, Christine. A pesquisa biográfica: projeto epistemológico e perspectivas metodológicas. In: PASSEGI, Maria da Conceição; ABRAHÃO, Maria Helena Menna Barreto. (Orgs.). Dimensões epistemológicas e metodológicas da pesquisa (auto)biográfica. Tomo I. Natal: EDUFRN; Porto Alegre: EDIPUCRS; Salvador: EDUNEB, 2012. p. 71-94.

DOMINICÉ, Pierre. O processo de formação e alguns dos seus componentes relacionais. In: FINGER, Mathias; NÓVOA, António. 0 método (auto)biográfico e a formação. São Paulo: Paulus; Natal: EDUFRN, 2010a. p. 81-96.

O que a vida thes ensinou. In: FINGER, Mathias; NÓVOA, António. 0 método (auto) biográfico e a formação. São Paulo: Paulus; Natal: EDUFRN, 2010b. p. 189-222.

EDDY, Martha. A brief history of somatic practices and dance: historical development of the field of somatic education and its relationship to dance. Journal of Dance and Somatic Practices, Coventry,v. 1, n. 1, p. 5-27, 2009.

FERNANDES, Ciane. Pina Bausch e o Wuppertal Dança-teatro: repetição e transformação. São Paulo: Editora Hucitec, 2007.

FERRAROTTI, Franco. Sobre a autonomia do método biográfico. In: FINGER, Mathias; NÓVOA, António. (Orgs.). 0 método (auto)biográfico e a formação. São Paulo: Paulus; Natal: EDUFRN, 2010. p. 21-58.

FIGUEIREDO, Ricardo Carvalho de; PEREIRA, Ana Cristina. (Orgs.). Formação, experiência e criação: 
curso educação infantil, infâncias e arte. Belo Horizonte: UFMG/FaE, 2014.

FORTIN, Sylvie. Living in movement. Development of somatics practices in different cultures. Journal of Dance Education, v. 2, n. 4, p. 128-136, 2002.

FORTUNA, Tânia Ramos. Ludobiografia: uma invenção metodológica em pesquisa (auto)biográfica em educação. In: PASSEGI, Maria da Conceição; ABRAHÃO, Maria Helena Menna Barreto. (Orgs.). Dimensões epistemológicas e metodológicas da pesquisa (auto)biográfica. Tomo II. Natal: EDUFRN; Porto Alegre: EDIPUCRS; Salvador: EDUNEB, 2012. p. 165-202,

FREIRE, Paulo. Pedagogia do oprimido. 17. ed. Rio de Janeiro: Paz e Terra, 1987.

GIORDANO, Davi. Teatro documentário brasileiro e argentino: o biodrama como a busca pela teatralidade do comum. Porto Alegre: Armazém Digital, 2014.

O homem vermelho: dança, autobiografia e doença na cena contemporânea. In: Semana Acadêmica, Semana Japonesa, 1., 2015, São João Del Rei. ASACT, São João Del Rei, UFSJ, n. 1, p. 83-93.

GREBLER, Betti. Pina Bausch e Maguy Marin: teatralidade e corporeidade contemporânea. In: XAVIER, Jussara; MEYER, Sandra; TORRES, Vera. Coleção dança cênica: Pesquisas em dança, v. 1. Joinville: Letra D’Água, 2008. p. 101-107.

GREEN, Jill. Somatic knowledge: the body as content and methodology in dance education. Journal of Dance Education, v. 2, n. 4, p. 114-118, 2002.

HANNA, Thomas. What is somatics? Somatics: Magazine-Journal of the Bodily Arts and Sciences, $p$. 4-6, 1986/88. Disponivel em: <http://somatics.org/ library/htl-wis4.html> Acesso em: 06 out. 2013

.The field of somatics. SOMATICS: MagazineJournal of the Bodily Arts and Sciences, v. I, n. 1, outono 1976.

JOSSO, Marie-Christine. Experiências de vida e formação. São Paulo: Cortez, 2004.

KOFES, Suely. E sobre o corpo, não é o próprio corpo que fala? Ou, o discurso desse corpo sobre o qual se fala. In: BRUHNS, Heloisa T. (Org). Conversando sobre o corpo. Campinas: Papirus, 1985. p. 44-60.

LANI-BAYLE, Martine. Narrativas de vida: motivos, limites e perspectivas. In: PASSEGI, Maria da Conceição; ABRAHÃO, Maria Helena Menna Barreto. (Orgs.). Dimensões epistemológicas e metodológicas da pesquisa (auto)biográfica. Tomo II. Natal: EDUFRN; Porto Alegre: EDIPUCRS; Salvador: EDUNEB, 2012. p. 59-78

LARROSA, Jorge. Pedagogia profana: danças, piruetas e mascaradas. 4. ed. Belo Horizonte: Autêntica, 2006.

LEAL, Maria Lucia. Máquina da memória. In: TAVARES, Joana Ribeiro da Silva; KEISERMAN, Nara. (Orgs.). 0 corpo cênico: entre a dança e o teatro. São Paulo: Annablume; Rio de Janeiro: Unirio; Capes, 2013. p. 277-289.

MACHADO, Suely. A importância da memória e do olhar na construção de uma linguagem artística. In: INSTITUTO FESTIVAL DE DANÇA DE JOINVILLE, Seminários de Dança - Criação, ética, pa..ra..rá pa..ra.. rá, modos de criação, processos que deságuam em uma reflexão ética. Joinville: Instituto Festival de Dança de Joinville, 2012. p. 70-74.

MUNDIM, Ana Carolina. Danças brasileiras contemporâneas: um caleidoscópio. São Paulo: Annablume, 2013.

OLIVEIRA, Valeska Fortes. A escrita como dispositivo na formação de professores. In: PERES, Lúcia Maria Vaz; ZANELLA, Andrisa Kemel. (Orgs.). Escritas de autobiografias educativas: o que dizemos e o que elas nos dizem? Curitiba: CRV, 2011. p. 123-135.

PERES, Bruna Bellinazzi. Desvelando memórias: afetos e autobiografia cênica. Rascunhos, Uberlândia, v. 1, n. 1 p. 76-88, jan./jun. 2014.

PERES, Lúcia Maria Vaz. No vai e vem da vida a escrita como um processo de (auto)formação. In: PERES, Lúcia Maria Vaz; ZANELLA, Andrisa Kemel. (Orgs.). Escritas de autobiografias educativas: o que dizemos e o que elas nos dizem? Curitiba: CRV, 2011. p. 65-78. 
RAMALHO, Betânia Leite; NUNEZ, Isauro Beltrán; GAUTHIER, Clermont. Formar o professor, profissionalizar o ensino: perspectivas e desafios. Porto Alegre: Sulina, 2004.

RIBEIRO, António Pinto. Por exemplo a cadeira: ensaio sobre as artes do corpo. Lisboa: Cotovia, 1997. Glória, glória ao corpo. In: RIBEIRO, António Pinto. Dança temporariamente contemporânea. Lisboa: Passagens, 1994. p. 9-21.

RIBEIRO, Mônica. Memórias na dança-improvisação: acontecimento do corpo. In: SILVA, Monica Toledo. (Org.). Performances da memória. Belo Horizonte: Impressões de Minas, 2013. p. 46-59

SALOMÃO, Waly. 0 mel do melhor. Rio de Janeiro: Rocco, 2001.

SANTANA, Eduardo Augusto Rosa. Dança autobiográfica: multivocalidade do self encenado a partir e além da carne negra. 2010. 109 f. Dissertação (Mestrado em Dança) - Programa de Pós-Graduação em Dança, Universidade Federal da Bahia, Salvador, 2010.

SHAPIRO, Sherry B. Em direção a professores transformadores: perspectivas feminista e crítica no ensino de dança. Pro-Posições, Campinas, v. 9, n. 2 (26), p. 35-53, jun. 1998.

SOUZA, Elizeu Clementino de. A arte de contar e trocar experiências: reflexões teórico-metodológicas sobre história de vida em formação. Revista Educação em Questão, Natal, EDUFRN, v. 25, n. 11, p. 22-39, jan./abr. 2006.

STINSON, Susan. Uma pedagogia feminista para a dança da criança. Pro-posições, Campinas, v. 6, n. 3, p. 77-89, nov.1995.

STRAZZACAPPA, Marcia. Educação somática: princí- pios e possíveis desdobramentos. Repertório - Teatro e Dança, Salvador, ano 12, n. 13, p. 48-54, 2009.2.

TIBURI, Marcia; ROCHA, Thereza. Diálogo dança. São Paulo: Editora SENAC, 2012.

TOLEDO, Monica. Memórias possíveis: eu em algum lugar. In: SILVA, Monica Toledo. (Org.). Performances da memória. Belo Horizonte: Impressões de Minas, 2013. p. $60-79$

TRAVI, Maria Tereza Furtado. Dançar-se: processos de criação em dança contemporânea. Cena em movimento, Porto Alegre, n. 3, s.n., 2013.

VIANNA, Angel; CASTILHO, Jacyan. Percebendo o corpo. In: GARCIA, Regina Leite. (Org.). 0 corpo que fala dentro e fora da escola. Rio de Janeiro: DP\&A, 2002. p. 17-34.

VIEIRA, Marcílio de Souza. A memória gruda na pele ou a dança madura do corpo. Art Research Brasil, v. 3, n. 2, p. 160- -177, jul./dez. 2016.

WEGNER, Bárbara Pires. Reelaboração de uma trajetória através da escrita de um diário. In: PERES, Lúcia Maria Vaz; ZANELLA, Andrisa Kemel. (Orgs.). Escritas de autobiografias educativas: 0 que dizemos e o que elas nos dizem? Curitiba: CRV, 2011. p. 27-35.

WOODRUFF, Dianne. Treinamento na dança: visões mecanicistas e holísticas. Cadernos do GIPE-CIT, Salvador, n. 2, p. 17-30, fev. 1999.

ZANELLA, Andrisa Kemel. Onde está a biografia do meu corpo? In: PERES, Lúcia Maria Vaz; ZANELLA, Andrisa Kemel. (Org.). Escritas de autobiografias educativas: o que dizemos e o que elas nos dizem? Curitiba: CRV, 2011. p. 9-26.

Recebido em: 10.01.2017

Aprovado em: 30.03.2017

Neila Cristina Baldi é doutoranda em Artes Cênicas pela Universidade Federal da Bahia. Mestra em Artes Cênicas. Grupo de Pesquisa Interdisciplinar de Pesquisa e Extensão em Contemporaneidade, Imaginário e Teatralidade. Bolsista CAPES. e-mail: neilabaldi@gmail.com

Universidade Federal da Bahia. Av. Araújo Pinho,292, Canela - Salvador, BA CEP 40110-150 Telefone: (51) 982.004.139 